\title{
Language Testing: an Overview and Language Testing in Educational Institutions of Bangladesh
}

\author{
Md. Mahroof Hossain (Corresponding author) \\ Department of English, Z.H Sikder University of Science \& Technology \\ Bhedorgonj, Modhopur, Kartikpur, Shariatpur, Bangladesh \\ E-mail: Mahroof.hossainsarker@gmail.com \\ Md. Kawser Ahmed \\ Z.H Sikder University of Science and Technology, Bangladesh \\ E-mail: kawser.zhsust@gmail.com
}

Doi:10.7575/aiac.alls.v.6n.6p.80

URL: http://dx.doi.org/10.7575/aiac.alls.v.6n.6p.80
Received: 13/06/2015

Accepted: 05/09/2015

\begin{abstract}
Test is procedures for measuring ability, knowledge or performance. Testing can be defined as a method of assessment and improvement of the students. Language testing in any point is an extremely multifarious task that ought to be based on method as well as exercise. The results of assessments are used for one or more purposes. So they have an effect on those who are assessed and on those who use results. The knowledge of the fundamental doctrine of testing is important for the instructor, as instructors have to make test for the institution as well as for the candidates of the external examination. Many instructors to do have the right knowledge about testing so that the language test may have harmful effect on education any they fail to measure what they want to measure. This study aimed mainly of clarifications of notions of testing system, its impacts on education process and the different steps for a qualified test development. This article also presents the characteristics of good test as well as it presents a study which is based on the university students about the test technique that is commonly used in educational institution of Bangladesh. This article will be helpful for the instructors to develop their testing system and make their teaching an effective one for the students.
\end{abstract}

Keywords: Language testing, Evaluation and assessment, EFL context

\section{Introduction}

Today practical language learning is taking place in various non-formal ways. Different organizations are taking many practical steps but the educational institutions cannot cope with these ones. If they fail to take up the newer ways, means and technologies, the whole language teaching learning can go to other sectors making the educational institutions lame. Life-oriented English must be taught to the students. Language is one of the medium of communication. Through communication one can express his or her idea, feelings and also share his problem to others and as well as can get the solution of the problem. Language is the most significant tool to make communication. Without language it becomes quite impossible for a human being to communicate his or her opinions to others and the educational process will not be possible to continue. This necessity compels us to learn a language and use the language suitably. To acquire a language or to learn a language is not an easy process, it requires a lot of uphill struggle to learn a language. The objective of this article is to help language teachers write better tests and by writing good test helps the students to acquire the target language. The whole article focused on the testing system; it presents the opinion that test construction is a matter of problem solving, with every teaching situation setting a different testing problem. A well constructed testing system is not enough to say that it is the appropriate test for testing the candidates. It also requires giving importance to the philosophy of testing and how they can be useful in practice.

\section{Testing}

Testing system is an essential part in teaching as it helps us to know the stage of the candidates or the students and depending on the level we as teachers can take advance steps for the development of their quality.

Testing system may have a constructive or unconstructive effect on the learners. Backwash is known as the effect of testing and learning. Language test construction and valuation describes the process of language test construction plainly and broadly.

Davies (1968:5) once wrote that 'the good test is an obedient servant since it follows and apes the teaching'. The proper connection between teaching and testing is surely that of partnership. It is true that there may be occasions when the teaching programme is potentially good and apt but the testing is not, we are then likely to experience from harmful backwash. This would seem to be the condition that led Davies in 1968 to confine testing to the role of servant to the teaching. But equally there may be occasions when the teaching is poor or inapt and when testing are able to make use of a beneficial influence. 
The main problem of tests is that often the test which is organized fail to measure accurately what they intended to determine. As a result student's true capabilities are not always reflected. Language abilities are not easy to evaluate. The first of the test is test content and test techniques.

Reliability is an important criterion for testing. Testing is reliable when it measures consistently. Unreliability has two factors. The first is the communication between the person taking the test and features of the test itself. As human beings are not machine and it is difficult for the human being to perform in exactly the same way on two different situations. As a result we get some dissimilarity in the scores a person gets on the test, depending on the time, mood of test takers. The second difficulty of unreliability is in the scoring process of a test. When we find different scores are given by different makers in the equal test to the same candidates the test become unreliable.

\section{Objectives of tests}

The main purpose of testing is to find out what the students have achieved at the end of the semester or what the progress of the student's is during the semester. This kind of assessment is known as formative and summative assessment. When teachers try to find out the improvement of their students, to observe how they have develop and to pinpoint out what they should have learned and finally use this information to modify their future teaching plans. This kind of assessment is known as formative. It can also be a kind of advice to the students.

When the assessment is used at the end of the term, semester or year with a view to measuring what has been gained both by groups and by individuals, this kind of assessment is known as summative assessment. So language testing system is important in our teaching arena.

A successful testing system should have the following criteria:

3.1 It should produce truthful measures of the abilities in which we are paying attention.

3.2 It has a useful effect on teaching

3.3 It should be cost-effective in terms of time and money.

3.4 It should be carried out in a proper way and fairness should be maintained.

\section{Different Types of Test}

Language test are carried out with specific intention in mind. As we use them to gain information about the students, we may categories tests according to the kinds of information being required. We may put them into the subsequent divisions:
a. Ability tests.
b. Situation test
c. Achievement tests.
d. Investigative test.
e. Aptitude test.

However, of the several tests mentioned above, achievement test will be the most appropriate one for someone who wants to find out how thriving a language programme has been.

\subsection{Ability test}

When it is intended to measure people's skill in a language without having any guidance in that language it is named as ability test. Ability test does not have any content or language course. The most renowned ability tests are Cambridge IELTS and the American TOEFL tests in that they want to have a picture of a candidate's ability to apply what they know. These kinds of test are very useful for future and often used by different education bodies, employers and immigration.

\subsection{Situational test}

Placement tests are designed to place students at an apposite level in a programme or course on the basis of their present level of proficiency. It is aim to find out new students into group roughly the same level. This type of test is not related to any type of course taken so that it start simple but get more difficult to furnish for a number of abilities. It is aimed to know the general standard rather than test exact language points. The fours skills of testing methods are usually based on common human experience- something everyone can rely on. An interview is useful as we gauge the student's spoken accuracy and fluency at the same time as putting a face to a filing number.

\subsection{Achievement test}

Achievement test is related to a particular course of study or programme. On the basis of their testing system it is categorized into two tests. One is final achievement test and another is progress achievement test. The main aim of achievement test is to find out what has been learnt over a longer period of time.

\subsection{Investigative test}

The most popular test to pinpoint the areas of difficulty the students faced as well as the strengths and weaknesses of the students is known as investigative test. The results also demonstrate which areas need revising with the class or individuals. 
Aptitude test assesses learner's 'aptitude' for learning a language. This type of test tries to measure the students' probable performances in a foreign language which he has not started to learn. There are many factors that are considered by aptitude test. These are intelligence, age, motivation, phonological sensitivity and sensitivity to grammatical patterning.

\section{Characteristics of good test}

All good tests possess three qualities: Validity, reliability and practicality. However, the supposition that good items will inevitably produce a good test may not always come true. Test developers, should go one more steps to determine the characteristics of the total test. In other words, simply putting good individual items together would not be sufficient for a test to function satisfactorily. (Farhady and Jafarpur and Birandi, 2010). To guarantee the quality of a test other factors and guiding principles including the administration process and scoring procedures are indispensable. In general it is noteworthy that an efficient test can be marked by certain characteristics that be considered as cornerstone of testing; reliability, validity and practicality. (Farhady, et..al,2010). It would be pointless to try to write tests without basic understanding of the principles behind them. So, a teacher who is constructing his own test or selecting a standard instrument for use in his class or school understands what these concepts mean and how to apply them.

\subsection{Validity}

The first criterion of a good test is validity. When a test measures what it is believed to measures it is known as validity. A number of producers are related to determine the validity. One producers is what exactly the test measures and another is how well the test measures.

\subsection{Reliability}

The perception of reliability is defined as 'the consistency of measurement' (Bachman and Palmer 1996). In other words, a test is reliable to the degree that whatever it measures, it measures it every time. Reliability may be of two types: test reliability and scorer reliability. Thus, to be reliable a test must not be resilient in its measurement. Reliability should focus on students score that the students should produce the same scores regardless of how many version of test the candidates takes.

\subsection{Practicality}

The focal point of practicality is management system. It is not enough for a test to be highly reliable and valid it should it should also be easy and cheap to construct, administer, score and interpret. So practicality is closely related to costcutting measures in time and in money.

\section{Common test techniques that are used in different educational institution in Bangladesh}

Test techniques are important to validate students correctly. Test techniques are one kind of techniques that are used to point out the behaviour of candidates that will tell us about their language skills.

According to Hughes (2003) what we need are techniques that:

7.1. Will extract behavior which is reliable and valid pointer of the ability in which we are interested.

7.2 will elicit behavior which can be reliably scored.

7.3 are as cost-effective of time and effort as possible

7.4 will have a beneficial backwash effect, where this is pertinent.

\section{Multiple Choices}

Multiple choice items take many forms, but their basic structure is as follows:

There is a 'stem'

Arif has been here ------ half an hour

And a number of 'options', one of which is correct, the others being 'distractors'. It is the candidate's task to identify the correct or most suitable option. Multiple choice scoring is fast and cost-effective. A further significant advantage is that since in order to response the candidate has only to make a mark on the paper. As it is possible to include more items; so that it is likely to make for greater test reliability. The difficulties with multiple choice areas as follows:

8.1 The technique tests only recognition knowledge

8.2 Sometimes guessing can bring unknowable outcome on test scores.

8.3 It restricts what can be tested.

8.4 It is very complicated to write successful items.

8.5 It is easy to cheat.

8.6 Backwash may be harmful.

\section{Yes/No and True/False items}

Where in multiple choice we have several choices to choose the correct option, but in Yes/No or true / false items we have only two option to choose the correct option. One of the pitfalls of such items is that the test of such items is that the test taker has a $50 \%$ chance of choosing the correct response by chance alone. 


\section{Short-answer items}

In listening and reading test short answer is a common test technique. It has particular advantage over the multiple choices

a. Guessing will contribute less to test scores;

b. The technique is not limited by the need for distractors.

c. Cheating is likely to be more difficult.

d. Items are easier to write.

The disadvantage of this kind of item is that responses may take longer and so reduce the possible number of items. Another disadvantage is that the test taker has to produce language in order to respond. Scoring may take longer.

\section{Gap filling items}

Filling a gap with a word is also a common technique in testing. Gap filling items for reading or listening work best if the missing words are to be found in the text. For testing grammar and vocabulary gap filling items can help a lot. But it does not work well where the grammatical element to be tested is discontinuous and so need more than one gap. If in testing the gap filling item is used it is essential for the test takers to give clear instruction that only one word can be put in each gap. In respect of this criterion we can value gap filling items highly. It is valued because it has advantages of the short answer technique.

\section{A Study}

In this section, we shall look in detail at a study which was made to find out the success rate of language test techniques that are used in the educational institution of Bangladesh.

\subsection{Area of investigation}

It is true that students are still unable to communicate in English in their daily life in spite they attain good grades in the public examination in our country. So, It is necessary to change the evaluation system to find out whether students are becoming proficient at key test vocabulary, grammar and idioms; however, this will not help the students in gaining effective balanced skills that combine listening, speaking, reading and writing competencies. So there are lots of complexities in preparing language testing items for a test.

\subsection{Objectives}

The study was conducted to achieve the following objectives:

a. To find out whether the item used in test are beneficial for the students.

b. To find out the item used in language testing is probing successful in language testing.

c. To find whether the existing language testing system are helpful for the students to learn English.

d. To find out the students suggestions how they think the language testing item should be improved.

\subsection{Questionnaires}

There is no scope of taking questionnaire lightly because it is a powerful tool for evaluation. It is seen that at present closed format questions are chosen. Except some Yes/No questions, all are the multiple-choice questions, which offer a number of answer options. Closed format questions have many advantages in respect of time, efforts and money.

\subsection{Subjects}

Subjects were 300 students of a University named Z.H Sikder University of science and Technology. All of them were native speakers of Bangla who were enrolled in two different course named Basic English language and Functional English and who were judged to be an intermediate -high level of proficiency in English.

\subsection{Research Methodology}

The present research was a descriptive survey type study. The researchers provide a question paper to all the students. The students are asked to answer the questions provided to them.

\subsection{Procedure of data collection}

After providing the questionnaire form, the researcher has collected the information from different classes and the total number of students was about 300 . The collected data were about 300 . The collected data were analyzed through the application of percentage.

\subsection{Results}

The study was conducted on 300 students among them different types of answers were given by the students.

Most of the students that is around $86 \%$ students said that the items provided to them in exam for language development is appropriate.

They were provided a question that which item is useful for language development. Around $60 \%$ give the answer that multiple choices help them a lot in language development other than other language item used in the exam for language testing. 
Around $75 \%$ students give the opinion that the language item used in the language test makes us to use accurate grammar in language.

Around $80 \%$ students give the following suggestion how the testing system should be and which item they think should be included in the language item.

a. Language items should focus on grammar.

c. Multiple choices help us to develop our reading skills. So multiple choices item should be included in language testing system.

d. The language item should focus on all the four skills reading, writing, listening and speaking.

e. Fill in the gaps is effective for language testing because it helps to enrich vocabulary. Fill in the gaps is an effective item for language testing.

f. Language items should focus on creative skills.

g. Reliable testing item should be included in language testing system.



Figure 1. Diagram of the students' opinion given on different question shown in percentage

\section{Recommendations}

We need to take further steps to improve this stream of education. The following recommendations can help a lot for the improvement of this education system:

a. It is necessary to keep in mind the communicative approach while setting up the questions.

b. Every skill should be tested through different items.

c. It is necessary to set up innovative questions paper so that students can answer them using their knowledge of English.

d. It is necessary to change the question pattern every year so that the students will be encouraged to read, to learn instead of memorizing the textbook content.

\section{Conclusion}

Testing is an important part of teaching process. It can be defined as a discipline of teaching. Whilst Alderson (1997) and others have argued that testers have long been concerned with matters of fairness and that striving for fairness is an aspect of ethical behavior, others have separated the issue of ethics from validity, as an essential part of the professionalizing of language testing as a discipline (Davies 1997). Tests are frequently used as instrument of educational policy, and they can be very powerful. (Shohamy, 2001).

\section{References}

Hughes, A. (2003). Testing for language teachers. Cambridge university press.

Davies, A. (1968). Language testing symposium: a psycholinguistics perspective. Oxford: Oxford University press. Farhady, H., Jafarpur, A., and Birjandi, P. (2010). Testing language skills from theory to Practice. Iran: SAMT

Bachman, L.F., and Palmer A.S (1996). Language Testing in practice. Oxford. Oxford University Press.

Alderson, J.S. (1997). Ethics and Language Testing. Paper Presentation at the annual TESOL conventions, Orlando, Florida.

Davies, A, (1997). Demands of being Professional in language Testing. Language testing, 14(3).

Shohamy, E. (2001). The powers of Tests. London: Longman. 